Disclosures E. Sussman: None. B. Martin: None. M. Mlynash: None. M. Marks: None. D. Marcellus: None. G. Albers: None. M. Lansberg: None. R. Dodd: None. H. Do: None. J. Heit: None.

\section{0-035 IGNORE THE CORE: DOES RECENT ADMINISTRATION OF INTRAVENOUS IODINATED CONTRAST RENDER CORE INFARCT ESTIMATION INACCURATE UTILIZING THE AUTOMATED CT PERFUSION RAPID SOFTWARE?}

${ }^{1} \mathrm{~A}$ Copelan*, ${ }^{1} \mathrm{G}$ Drocton, ${ }^{2} \mathrm{E}$ Smith, ${ }^{1} \mathrm{R}$ Khangura, ${ }^{1} \mathrm{D}$ Murph, ${ }^{1} \mathrm{C}$ Dowd, ${ }^{1} \mathrm{~V}$ Halbach, ${ }^{1} \mathrm{R}$ Higashida, ${ }^{1} \mathrm{~S}$ Hetts, ${ }^{1} \mathrm{D}$ Cooke, ${ }^{1} \mathrm{M}$ Amans. ${ }^{1}$ Neurointerventional Radiology, University of California San Francisco, San Francisco, CA; ${ }^{2}$ Department of Radiology, Medical College of Wisconsin, Milwaukee, WI

\subsection{6/neurintsurg-2019-SNIS.35}

Background and Purpose Automated computed tomography perfusion (CTP) software is increasingly utilized to aid in treatment decisions in emergent large vessel occlusion (ELVO), particularly in extended window stroke patients. Neurointerventionalists must be cognizant of pitfalls of these software packages in predicting ischemic core and penumbra. This study aims to assess whether RAPID post-processing software underestimates core infarct in patients who have recently received intravenous iodinated contrast, a common scenario in stroke transfer patients who undergo CTA at an outside hospital to confirm ELVO prior to transfer.

Methods We retrospectively reviewed 271 consecutive patients at our institution who underwent CTA \pm CTP for symptoms of acute ischemic stroke (AIS) from May 2018 through January 2019. Patient exclusion was predominantly on the basis of lack of anterior circulation ELVO on CTA or lack of performance of CTP with RAPID post-processing. Two blinded raters independently assessed CT Alberta Stroke Program Early Computed Tomography Score (ASPECTS) on the non-enhanced head CT (NECT) at the time of CTP and also collected clinical as well imaging data, including time from last known well (LKW) to CTP, collaterals grade, and core infarct $(\mathrm{mL})$ as predicted by RAPID software. Patients were dichotomized into those who received recent intravenous contrast (within 12 hours of CTP) and contrast naïve patients. Correlation between ASPECTS and core infarct $(\mathrm{mL})$ on RAPID software were analyzed for the two cohorts.

Results A total of 48 patients with a mean age of 74.1 years (SD 16.4) were included. The two cohorts comprised 24 patients each. There were baseline differences in mean ASPECTS (8.5 vs 5.6, p<0.001) and time from LKN to CTP acquisition (469 mins vs 740 mins, $p<0.001$ ) in the contrast naïve and prior contrast groups, respectively. However, when adjusting for these variables on multivariate regression analysis, there is a statistically significant difference in core infarct per RAPID, with underestimation of core infarct in those patients who received recent contrast $(p=0.016)$. In addition, there was a stronger correlation between ASPECTS and core infarct per RAPID in the contrast naïve patients $(\mathrm{r}=-0.745)$ compared to those who received recent contrast $(r=-0.42)$.

Conclusion Patients that previously received contrast had a much higher likelihood of underestimation of ischemic core using RAPID than contrast naïve patients. Those involved in the care of ELVO patients should avoid overreliance on RAPID post-processing for treatment disposition, particularly if the patient has received recent intravenous contrast.

Disclosures A. Copelan: None. G. Drocton: None. E. Smith: None. R. Khangura: None. D. Murph: None. C. Dowd: None. V. Halbach: None. R. Higashida: None. S. Hetts: None. D. Cooke: None. M. Amans: None.

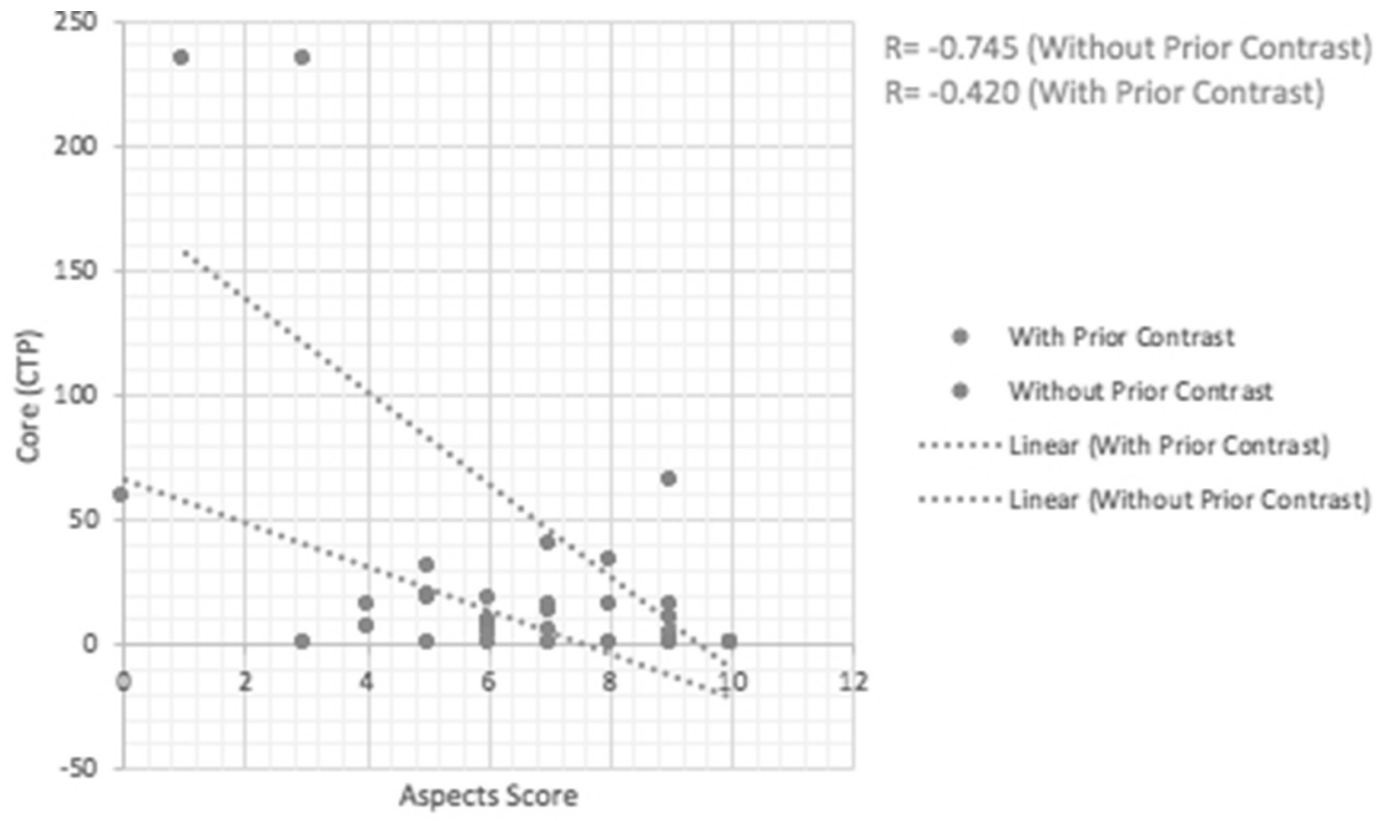

Abstract 0-035 Figure 1 